\title{
Resident Unions: Why we all need them
}

\section{Current Research in Emergency Medicine (CREM)}

\author{
Volume 1, Issue 2, 2021 \\ Article Information
}

Received date : 22 September, 2021

Published date: 01 October, 2021

*Corresponding author

Amelia Breyre, Department of Emergency Medicine, University of California San Francisco, USA

Distributed under: Creative Commons CC-BY 4.0

\author{
Amelia Breyre* \\ ${ }^{1}$ Department of Emergency Medicine, University of California San Francisco, USA
}

Opinion

Some things will always be true about residents -- they will always be at bedside any hour of any day, including late nights and holidays. They will be the first to tell someone their grandmother has died and then complete the litany of administrative tasks that come with death. However, residency has also changed significantly in recent years. Student debt is more daunting, [1] residents spend more time with computer records,[2] patient turnover is faster, and medical acuity is greater [3]. COVID-19 has added a multitude of additional challenges. Residents are learning medicine in a healthcare system where the demands of physicians are evolving. Residents need to be equipped to advocate for themselves and their patients through dynamic change. Unions can provide a mechanism to do just that. There are a variety of physician unions that exist in the United States; Committee of Interns and Residents (CIR), a local of the Service Employees International Union (SEIU), is the largest resident union, representing over 16,000 residents nationally. In 1958, residents of New York City's public hospitals who were dissatisfied with hospital conditions founded CIR. In 1975, CIR won contractual limits for on-call schedules to be no more than once every three nights. In the 1990s, CIR won pay for residents covering for absent colleagues, and contributed to state regulations that set maximum work hour limits. Sixty years since its founding, CIR continues to be a resident-run union whose core mission remains unchanged: "empower our nation's interns, residents and fellows to fight for excellence for our patients, our training and our healthcare system through organizing, collective bargaining and advocacy."

In the past three years, there has been a wave of California residencies unionizing, including UCSF, UCLA, UC Davis and UCLA-Olive View. The eagerness of residents to join unions is multifactorial and as diverse as residents themselves. Each resident has their own individual reasons. For some, the reasons are financial. The average medical student graduates with $\$ 200,000$ of debt, a number that rises steadily annually [4].The average internal medicine first year resident salary widely varies from $\$ 40,000$ to $\$ 70,000$ nationally. Although these salaries are well above the federal poverty line, they can still create a stressful financial burden when calculating an 80-hour workweek and compounding student debt interests. The issue is further aggravated with significant variation of salaries between programs that do not necessarily account for geographic variations in living costs [5]. In California, CIR has been pivotal in winning housing stipends for residents to offset the relatively high cost of living. Some CIR residents have hospital contracts that provide bonus pay to recognize the time they spend in hospitals during federal holidays. In aggregate these financial changes are empowering to young physicians.

Some residents joined a union to protect individual rights. For example, the right to have a family and still become a doctor. The American Academy of Pediatrics proposed federal law to support 12 weeks of paid family leave, however a survey of Graduate Medical Education (GME) institutional policies demonstrated the mean duration of paid childbearing leave was 5.7 weeks (range, 2-8weeks). In a national survey of 347 female general surgeons who were pregnant during residency, 29.5\% would discourage female medical students from a surgical career specifically because of the difficulties of balancing pregnancy and motherhood with training [6]. Unions provide a mechanism for residents to contractualize paid parental leave, enforce mandated lactation spaces be provided for breast feeding mothers, support childcare benefits and create a work environment that supports residents rights to have a family during their peak child bearing years. For others, unions provide a way to advocate for the most vulnerable patients. The majority of CIR members work at safety-net hospitals. Many chapters have a contractual patient care fund that provides a modest slush fund that can to make purchases to improve patient care needs that may be otherwise unmet. These funds have been used to purchase iPads to help facilitate language interpretation for non-English speaking patients or to buy cell phone charging stations for patients in clinic waiting rooms.

For many residents, unions provide an opportunity to improve job satisfaction and the balance between service and education. Resident duty hour restrictions have been contentiously debated. The FIRSTtrial [7] and iCOMPARE [8] trial involving surgery and internal medicine residents respectively demonstrated that stricter duty hours did not equate to greater resident satisfaction and patient outcomes. Both of these studies miss a key point in resident satisfaction; it is not the number of hours worked but the type of work done during those hours. Scut work is "the repetitive, minimally educational chores that are a major part of most residents daily work" [9]. Resident physicians can have tremendous responsibilities in the workplace yet may feel that they control very little. It is this lack of control that directly contributes to the hotly discussed topic of resident burnout, depression and suicide [10-12]

The residency union at Boston Medical Center, created an ancillary services committee that used resident surveys to identify non-educational tasks (i.e. scut work) and develop solutions with administration leadership. The committee reworked the way PICC (peripherally inserted central catheter) consent was obtained. Instead of residents, who were not performing the procedure, obtaining consent form patients, specially-trained nurses would discuss the procedure, obtain consent and perform the procedure on patients. This was an elegant and simple solution to minimize scut work. As residents navigate the delicate balance between service and education, unions provide a voice to advocate for better patient safety protections, better educational experiences and work satisfaction. As COVID-19 has strained our health care system, Accreditation Council for Graduate Medical Education (ACGME), the accrediting body for residency programs, released statements that publicly defends resident safety and rights. They clearly stated that residents must have proper personal protective equipment, must be supervised by faculty who understand their capability and capacity in the service to which they are assigned, and that furloughs of residents are unacceptable [13].

Although ACGME does protect residents who are vulnerable to exploitation in many scenarios, they inevitably fall short since their primary objective as monitors of educational standards and not labor rights activists. For example, many residents also want access to routine COVID testing, protected COVID sick leave and a clear mechanism to report safety concerns without fear of reprisal from their programs. Unions provide a protected pathway for residents to safely express their labor concerns, many of which are without precedent given the novelty of the pandemic. There exists tremendous opportunity for collaboration 
between ACGME and resident unions to address challenges in a multifaceted and powerful way. Residents will always be the frontline of medicine. We will always know the pulse of healthcare in a more humanist way than hospital administrators because of the nature of our job. Unions bring residents together to provide invaluable lessons -- how to advocate for one's own well-being, how to organize and to make a health system better how to make improvements in the workplace, and how to empower residents' idealism with action. All physicians should encourage the growth of unions and the personal and professional power that they provide young doctors. The collective ability of residents to organize and advocate is a powerful tool that makes residents into true agents of change.

\section{References}

1. Phillips JP, Peterson LE, Fang B, Kovar GI, Phillips RL (2019) Debt and the Emerging Physician Workforce: The Relationship Between Educational Debt and Family Medicine Residents' Practice and Fellowship Intentions. Academic medicine: journal of the Association of American Medical Colleges 94(2): 267-

2. Chen L, Guo U, Illipparambil LC (2016) Racing Against the Clock: Internal Medicine Residents' Time Spent On Electronic Health Records. Journal of graduate medical education 8(1): 39-44

3. Association AH (2013) Issue Brief: Sicker, More Complex Patients are Driving up Intensity of ED Care.

4. Colleges AoAM (2018) Medical student education: debt, costs, and loan repayment fact card. Washington, DC: Association of American Medical Colleges.
5. Pasha AS, Al Shabeeb R (2019) Do Differences in Internal Medicine Resident Salaries Correlate with Variation in Regional Cost of Living? Journal of general internal medicine 35(8): 2508-2509.

6. Rangel EL, Lyu H, Haider AH, Castillo AM, Doherty GM, et al. (2018) Factors Associated With Residency and Career Dissatisfaction in Childbearing Surgical Residents. JAMA surgery153(11): 1004-1011.

7. Bilimoria KY, Chung JW, Hedges LV (2016) National Cluster-Randomized Trial of Duty-Hour Flexibility in Surgical Training. The New England journal of medicine 374(8): 713-727.

8. Desai SV, Asch DA, Bellini LM, Krisda CH, Manquing L, et al. (2018) Education Outcomes in a Duty-Hour Flexibility Trial in Internal Medicine. The New England journal of medicine 378(16): 1494-1508.

9. Hayward RS, Rockwood K, Sheehan GJ, Bass EB (1991) A phenomenology of scut. Annals of internal medicine 115(5): 372-376.

10. Shanafelt TD, Bradley KA, Wipf JE, Back AL (2002) Burnout and self-reported patient care in an internal medicine residency program. Annals of internal medicine 136(5): 358-367.

11. Thomas NK (2004) Resident burnout. Jama 292(23): 2880-2889.

12. Stehman CR, Testo Z, Gershaw RS, Kellogg AR (2019) Burnout, Drop Out, Suicide: Physician Loss in Emergency Medicine, Part I. The western journal of emergency medicine 20(3): 485-494.

13. (2020) ACGME Reaffirms its Four ongoing Requirement Priorities during COVID-19 Pandemic. 